\title{
Compliance, engagement and commitment: Increasing employer expenditure in training
}

\author{
Stephen Billett (Griffith University, Australia) and \\ Andrew Smith (Charles Sturt University, Australia)
}

Billett, S \& Smith, A (2003) Compliance, engagement and commitment: Increasing employer expenditure in training. Journal of Vocational Education and Training, 55 (3) 251-269

Internationally, governments are keen to identify and enact policies to encourage increased contributions from enterprises for the skill development of their employees. However, the goals for these policies often remain unclear and the means of securing these purposes are vexed. Drawing on a review of international literature and interviews with expert informants, a series of policy options are discussed and evaluated in this paper in the Australian context. These options include mandated national levies, sectoral and local levies, regulated licensing, schemes that seek to share the cost burden and those that aim to change employers' attitude towards vocational education and training. In considering what policy options are most viable, evidence from their implementation elsewhere are used to discuss and predict the utility and likely outcomes of those measures being implemented in Australia. In all, schemes that involve, include and capture the interest of employers are held to be the most desirable and likely to be supported. Yet, even these may not be able to achieve goals of a fuller commitment to and an equal distribution of opportunities for all workers. Although Australia serves as the focus for this paper, its deliberations probably have implications elsewhere.

\section{A common policy concern}

Governments in Europe, the Americas, and Asia as well as those in Australia have enacted policies and practices that aim to increase employer contributions to the skill development of their employees. Yet, the goals for these policies often remain unclear and the means of securing them are complex and vexed. For instance, contrary common belief in policy circles, it seems that the current level of expenditure by Australian enterprises compare favourably with those of many other countries, including some with strong traditions of employer commitment to training (Smith \& Billett 2003). So while there is room for improvement, an important issue is how to best achieve this, without causing resentment, that may erode the existing level of commitment as occurred with the implementation of a national training levy in the 1990s. Policy mechanisms for achieving improvement will need to be carefully considered, selected and implemented judiciously. Such measures require consideration of the particular circumstances, antecedent conditions and goals attempting to be achieved. Therefore, the diverse approaches trialled in other countries provide options to be considered for a particular national, sectoral or even locally based initiative that attempts to increase enterprise expenditure on training. Such options seem important because no one approach will address the needs of a country like Australia with its diverse industry sectors, sizes of enterprise and their widespread distribution, as well as different needs.

This paper discusses policy options for increasing expenditure by enterprises on developing their employees' skills. Drawing on a review of international literature and interviews with expert informants, a series of policy options are discussed and evaluated. Policy measures by which this goal might be achieved range from those that aim to compel employers through mandation and legislation to those that seek to 
generate a voluntary commitment to expenditure on training. In considering the utility of these options, it is proposed that, in general, compulsion is ultimately likely to be counter productive. Where a positive sentiment exists or can be generated there may be room for sector specific or local levies. Then there are mandated arrangements such as licensing and certification. Yet, overall, the findings indicate that in modern pluralistic countries with diverse economies and complex relations between enterprises and government, between enterprises and representative bodies, and among enterprises, no single mechanism will be sufficient to achieve this goal, as there are quite different premises and bases for securing this goal across industry sectors. Short-term measures may focus upon impositions of different kinds. Yet, the most sustainable approach will likely reside in finding ways of elevating the understanding of the worth of vocational skills and encouraging enterprises to see such expenditure as being beneficial both for their immediate and long-term purposes. Although this paper takes Australia as its focus, its deliberations will likely have resonance elsewhere.

\section{Increasing enterprise expenditure on training}

Securing an increased level of spending by Australian enterprises on the initial preparation and on-going development of their employees is no easy task, nor is it likely to be achieved in the short term. Although it is possible to compel enterprises to make contributions to the cost and provision of training, to date such actions have largely been unsuccessful and appear to erode existing enterprise commitment to and sponsorship of vocational training. For instance, the experience in Australia is that a national training levy in the form of the Training Guarantee Scheme during the early 1990s succeeded in highlighting the cost of training by mandating a certain level of enterprises expenditure or having to pay the shortfall as a tax. Linking this Scheme to the tax system did little to persuade enterprises that expenditure on training was a strategic and prudent investment, rather than a cost for Australian employers.

Research in Australia and overseas has shown that the primary drivers for enterprise investment in training are internal - most commonly they have to do with making business sense. Smith and Hayton (1999) identified the main drivers for training provision in enterprises as being related to organisational change and the introduction of new technologies. Yet, the training arrangements that eventually developed were the product of factors such as the size of the enterprise, the occupational structure of the workforce and its industrial relations climate. Further work on the relationship of organisational change to training has shown that whereas change processes are an important factor in driving investment in training at the enterprise level, the critical factor in the process is the relationship of training to enterprises' business strategy (Smith et al, 2003). Thus, attempts to encourage employers to make greater investments in training will need to appeal to the strategic interests of enterprises if they are to succeed. For instance, Billett \& Hayes (2000) reported that enterprises in the food processing sector, which admittedly has little history of structured training arrangements, would expend funds on staff meeting the requirements of Food Handling legislation or when they wanted to change their manufacturing processes, but were reluctant to expend beyond that.

Nevertheless, in recent data on training practices, Australian employers nominate staff development and enhancing the skill currency of their employees as the main reasons for providing training (Australian Bureau of Statistics, 2003). Given current attitudes and from previous experiences, it would seem that enterprises and the national bodies that represent their interests would need to be convinced that expenditure on training would provide a direct return in terms of improved productivity or services. It 
might be thought that such outcomes would be identified through cost-benefit analyses of training and vocational education. However, at the enterprise level these have proved difficult and impractical. Enterprises have reported appropriate difficulty in identifying and appraising what contributions training makes to productivity or enhanced service (e.g. Hedge \& Moss 1996), let alone measuring those contributions (Bartels 2000, Robinson \& Robinson 1989). However, recent research in Australia shows that the returns to training investments can be identified and quantified if the correct methods are used (Smith, 2001). These studies have shown that the returns to training investments are high, often in the order of hundreds to one and that training is one of the most profitable investments that businesses can make. Perhaps a task for the VET sector is to assist employers use these approaches more effectively and enable them to identify the returns that training can make to their businesses. Yet, currently it seems that, internationally, few enterprises use cost benefit analysis to make decisions about expenditure on training (Carnevale \& Schulz 1990, Davidson et al 1997, Coopers \& Lybrand 1996). Instead, they seem to rely on perceptions of its utility or capacity to achieve strategic goals (Billett 1994, Davidson et al 1997). Hence, enterprise perceptions of the worth of training likely determine the levels of their expenditure.

In some European countries, there is a stronger commitment to skill development that shapes enterprises' expenditure on training, which obviates the need for cost benefit analysis. Sometimes the motivation for the apparently more generous approach to expenditure on training is quite pragmatic. The basis of this voluntary action can be to maintain enterprise control or to participate at a level to avoid external control of enterprises' expenditure on training by government (e.g. Schweri 2002). Moreover, the French experience (Giraud 2002) suggests that when enterprises have contributed to a levy system, they are reluctant to provide all staff with further training, to avoid incurring costs additional (e.g. worker absenteeism) to those they have already expended via the levy. Analogously, Wolf (1996) reports from research across OECD countries that employers will pay for the development of current specific skills and some generic skills that will lead toward achieving the enterprises' strategic goals. So the attitude of Australian employers may not be wholly different from those elsewhere. However, where there is evidence of a firmer and enduring commitment to skill development by enterprises it is in those countries that have institutional sentiments and practices associated with a social charter of some kind. The kind of sentiments that underpins this charter offers some lessons to be learnt and policy options to be considered for Australia and perhaps elsewhere.

Before discussing options for increasing enterprises' expenditure on the skill development of their workers, the following conditions are worth noting. Firstly, enterprises of all kinds and sizes already make considerable contributions to the initial preparation and ongoing development of their staff through the support for learning that occurs as part of everyday work activities (Bishop 1997) and also through structured programs such as apprenticeships. The quantum of this contribution may not be fully appreciated by government and commentators who are concerned to equate expenditure on training only with participation in courses or those elements of courses that occur in training facilities. As noted, the estimated total expenditure by Australian employers on training is not low by international standards. At over $\$ 4$ billion in 2002, employer expenditure is higher than government expenditure on vocational education and training at a little over $\$ 3.5$ billion. Beyond the level of funding, it is the quality and the distribution of the training that is provided that is at question, rather than the quantity.

Secondly, enterprises in some industry sectors hold the view that the existing vocational education and training system fails to meet their needs e.g. small businesses 
(Roffey et al 1996, Coopers \& Lybrand 1994), so would probably resist contributing further. In particular, those enterprises that are located within industry sectors that have not traditionally been the focus of properly funded vocational education training provision may question their existing contributions to training system which fails to recognise their existence, let alone their needs.

Thirdly, it is not always clear what goal government is trying to achieve through seeking enhanced expenditure on vocational training by Australian enterprises. Responses to government policies may be quite different when enterprises see them as: (i) merely concerned to pass onto enterprises the cost of training; (ii) attempting to secure greater equity in enterprise expenditure; (iii) having a clear focus on building sector specific skills; or (iv) developing the capacities of the enterprise's, the region or national workforce. The purposes of the policy will also shape the measures that might be applied. If, for instance, the goal for policy is to ensure enterprises carry a greater share of the cost of the national vocational education system, then these measures might be largely focused on enterprise sponsorship of accredited courses. If, however, government is seeking an increase in the overall enterprise sponsorship of activities associated with skill development, then a broader range of policies would need to come into play. This might include an interest in the degree of expenditure on in-house training, the general education of employees, their participation in accredited programs, as well as support for effective on-job learning.

Overall, two broad categories of policy options are identified in the practices within Australia and overseas. These categories comprise either compelling or encouraging expenditure by enterprises on their employees' development. The first category is associated with the use of legislation and mandation to either stipulate engagement in structured training or levy funds to cover the cost of training, or through enterprise sponsorship of the certification or licensing of their employees' skills. The second category focuses on changing employer views about expenditure on training in order to generate an ongoing voluntary commitment to and sponsorship of vocational skill development.

\section{Compelling enterprises to contribute to skill development}

Options for compelling enterprise contributions to skill development are of two kinds. The first is about organising levies to cover the costs of training. The second is about mandating training for licensing arrangements and occupational certification. Both have different strengths and weaknesses and different prospects of gaining employer acceptance.

$\underline{\text { Levies }}$

Levies can take a number of different forms. The most common are national or universal levies. Others focus on the needs of a particular industry sector or are regional. While they may have a common mode of securing funds, the source of their inception and hence the bases for their support are often quite distinct.

\section{Universal Levy}

Universal levies can be used to ensure that most or all enterprises contribute to the cost of developing the skills of a nation's workforce. A number of such levies have operated or continue to operate. These include the Training Guarantee Scheme (TGS) in Australia, the Skills Development Fund (SDF) in Singapore, the Human Resource Development Fund (HRDF) in Malaysia, the Employer insurance Scheme (EIS) in South Korea and the French levy system. In all of these systems, most employers across the majority or all sectors of the economy are required to pay a levy into a training fund 
that can then be drawn upon to finance particular forms of training. The defunct Australian TGS was different in that it stipulated a level of expenditure and the levy was a penalty for non-compliance.

As a broad policy tool, levies are useful for either generating revenue or encouraging expenditure on training which was the intent with the TGS. Policy makers welcome them for their broad applicability. This is because, they might be able to shift part of the cost burden of vocational education from the private to the public sector, achieve greater equity in the distribution of the burden of the training effort across the nation's enterprises and, arguably, increase expenditure on training. However, they are not always popular or politically palatable. Moreover, the evidence suggests that the quality of vocational skill development that occurs under these arrangements may not be high. For instance, simply using participation in accredited training programs as a measure of legitimate training can be misleading. In France, this kind of scheme has failed to secure a high level of employer commitment to training for the kinds of high skill jobs being sought in Australia (Hall, Buchanan \& Considine 2002). Also, despite the levy system and its procedures to make it open to all employees, the reality is that the expenditure of funds within enterprises is ultimately subject to decision-making within enterprises. The basis for distributing training opportunities within enterprises is often premised on the measured and unmeasured abilities of workers, which has resulted in inequities in the distribution of those funds (Goux \& Maurin 2000 cited in Giraud 2002). So, despite having a national training levy, the opportunities for individuals to access training is shaped by workplace characteristics (e.g. size) and the worker's standing within the enterprise. Moreover, because they are mandated, they are likely to be resisted or complied with superficially. For instance, despite having a national training levy, only $58 \%$ of French workers reported receiving further training compared with $84 \%$ of workers in Germany, were no such levy is enacted (Giraud 2002). Therefore, there can be no guarantee that mandated levies will produce higher levels of participation in enterprise-based training.

Experience shows that in Australia and elsewhere, national levies tend to promote resistance and, or superficial compliance by enterprises. Thus, the HRDF in Malaysia and the EIS in Korea have done little to increase employee training in large firms (which are already training their employees) or stimulate small businesses to train more. An interesting counter-example is the SDF in Singapore. Although a universal levy, the Fund has been successful in significantly increasing the level of training given to low skilled workers. However, this is a function of tight targeting - the levy applies only to low skilled workers employed in Singaporean enterprises and can only be used to fund training for these workers. Employers have vested interest in training their workers in order to both avoid the levy on their wages and to increase their own skills base.

Furthermore, a great danger of using levies or demonstrating expenditure to avoid paying a levy is that these actions may lead to enterprises developing a tight focus on the cost of training employees. This can lead to all forms of workplace support as well as accredited vocational education programs being increasingly subject to financial scrutiny. In short, such measures may lead to the commodification of training, with all forms of assistance to learning being viewed as a cost. Moreover, the experience in both France and Australia is that national levies become highly contested and subject to constant negotiation of a kind that suggests little genuine commitment to vocational learning is generated by enterprises negotiating these measures. Furthermore, given their inability to influence decision-making within enterprises, national training levies are likely to entrench existing disadvantages, except when they are specifically targeted as with the SDF. The evidence suggests that those most in need of training will remain 
minor participants in these enterprise-funded arrangements (e.g. Krueger \& Rouse 1998).

\section{Sectoral levies}

Sectoral levies have been shown to work in some industry sectors (e.g. building and construction). It presents a more acceptable kind of levy to enterprises because it is sector specific and can be seen as being by the sector. The French experience with its national training levy suggests that enterprises are more accepting of localised and industry based levies, than a broad national levy (Brochier \& Meiaux, 1997 cited in Giraud, 2002). Changes made to the operation of the French training levy over time, have largely been to secure greater enterprise representation in agencies and at the local level that have control over the funds gathered through these levies. However, an industry based or sectoral levy is likely to be played out in different ways across different industry sectors. For instance, the contractual nature of the building and construction industry means that there is a reliance on the industry based workforce and a pool of skilled labour. Also, some governments have assisted the maintenance of the industry levy by demanding that contracts for public buildings include an industry training levy. Yet, such a levy is less imaginable across a industry sector dominated by a few major employers or those that have their own distinct patented products. So assumptions that the level of acceptance of industry-based levies have enjoyed in the building sector would be replicable in other sectors may be quite erroneous. As noted, the impact of such levies is debatable. In the Australian construction industry, the levy has not had a significant impact on the traditionally low level of employer provided training in that industry. However, a recent initiative in the State of Victoria is quite strategic and is providing funds for an area of skill development that has been long in decline, but now enjoys very high demand. Here, the Brick and Block layers have collectively and voluntarily agreed to a levy being applied to all purchases of bricks and blocks for the purposes of sustaining skills which are disappearing with the retirement of an ageing workforce. Of course, in this case directly, the cost of this training is being passed on to consumers and customers.

In the Netherlands, the $\mathrm{O}+\mathrm{O}$ Funds Scheme has also generated a high level of employer acceptance. This is partly a function of it not being legislated, but bargained for on a sectoral basis through collective agreements. However, the level of employer acceptance in the Netherlands does not alter the fact that only 40 per cent of the moneys collected through the $\mathrm{O}+\mathrm{O}$ Funds are spent on training with the rest being consumed by administration, and collectively the funds only accounting for about 5 per cent of total expenditure on employer training.

In policy terms, industry based levies provide a mechanism that could be used to shift the costs of vocational education to industry and achieve some sharing of expenditure across industry sectors. The industry levy may be a useful sector wide device to promote the strategic goals of the industry and enterprises within it when it is coupled with a body (e.g. professional or trade association, guild) that can promote the importance and standing of vocational skills, as is the case in the recent example of the brick and block levy in Victoria. If the tangible benefits of industry specific training are demonstrable, this approach may even increase expenditure on training by enterprises. However, in terms of other policy goals, a levy on its own it cannot guarantee increases in the quality of skill development nor the equity of the distribution of the expenditure within the workplace. Neither the mandated approach in Germany or the legislated levy in France has been able to influence how funds are spent within enterprises (Giraud 2002). Again a useful counter-example is the Singapore SDF system targeted on low 
skilled workers. However, the SDF operates in a very small country that has a highly centralised system of government and where people demonstrate a high level of commitment to the development of the State in ways very different to the pluralist traditions of countries such as Australia and those in Europe. It would be difficult to imagine such an approach gaining acceptance in more laissez-faire economic systems such as the United Kingdom and United States of America.

\section{Localised/regional levy}

Levies operating at the local or regional level offer the virtue of being potentially highly visible and pertinent to the enterprises in the local area. If there are particular needs in particular communities, there may well be some consensus about the gathering and expenditure of funds, or at least directing common effort towards those goals. For instance, the viticulture industry in South Australia identified the shortage of workers in a particular region (Billett \& Hayes 2000). Such was the concern of the industry that collectively they embarked on regional arrangements to encourage school leavers to consider working in the viticulture industry.

However, again taking the French experience, there would need to be arrangements that could convince local enterprises of the need for such a levy. Enterprises demand direct involvement with levy expenditure and administration, which they guard jealously (Giraud 2002). They also need to be able to witness its direct consequence for the skill base of their particular enterprises. Moreover, such arrangements are more likely to be successful in a community that has clearly identifiable physical or geographical parameters, rather than where the local area is illdefined. For instance, it may be easier to organise a local levy in an identifiable community like Gladstone in Queensland, which is separated from others by considerable distance and where there are a cluster of secondary processing companies that have a common set of needs (e.g. engineering and production workers). Added to this, is the containment of the workforce whose development is being sponsored across enterprises. Of course, there will be complications about the identity and representation of the geographical parameters of any localised levy. Funds might be expended on individuals who then leave the area. These conditions are distinct from the more heterogeneous and dispersed sets of needs that might arise in large cities

So localised arrangements may achieve a number of goals. They may shift and redistribute the cost of vocational skill development. If there is an identified need, an increase in expenditure may occur. However, taking the French experience the need for localised control and administration of such funds would seem to be an imperative. Importantly, if the local interest exists, issues of quality and commitment may well flow through more easily.

In summary, compulsion on employers to increase their investments in training through the use of levies does not enjoy a history of success. Universal levies in particular inspire superficial employer compliance and often outright resistance. The more targeted the system (as in Singapore) and the more localised the control and administration (as in the Dutch $\mathrm{O}+\mathrm{O}$ Funds and the French system) the more likely are employers to accept the levy. However, employer acceptance does not necessarily involve an increase in investment or a focus on quality of equity considerations, as the Dutch and French examples demonstrate.

Mandating licensing arrangements and occupational certification

Another compulsory approach to increasing training investment is through licensing arrangements. Currently, government mandates vocational training for a variety of 
reasons. Occupational licensing (e.g. plumbing, electrical work, pilots) usually exists because of inherent dangers, and where it is against the public interest for tasks to be undertaken without licensing (e.g. forklift, crane handling, boiler attendance) because of occupational health and safety requirements or where the work has particular requirements for care (e.g. food handling). These kinds of work require that individuals have undertaken training and been certified before they can work. One measure of levering additional expenditure from enterprises is to broaden the bases for licensing and certification required in the workplace. In England, government often stipulates that workers engaged in publicly funded activities (e.g. aged care) have to have particular certification. Therefore, employers are pressed to ensure that their employees undertake courses and assessment in order to secure the appropriate certification. There is a perception that this policy is being deliberately employed by government with the intent of levering greater commitment to training from employers (Keep 2003). So this measure represents another policy option for encouraging increased enterprise expenditure on training.

In policy terms, if this approach was adopted it may lead to the shifting of cost to the private sector, although it might be transferred either in part or in whole to the individuals who are to be certified or licensed. Increasing the range of licensed and certified occupations also focuses on the importance of the quality of the work to be done, rather than simply on cost issues. For those industries where there is little in the way of certification, such arrangements may also provide for much-needed formal recognition for the workers' skills in those sectors. As enterprises have been shown to expend funds when certification arrangements are mandated, some increase in expenditure could be expected. However, the need to licence has arisen for important social and environmental reasons. Therefore, it would be essential to ensure that broadening the licensing arrangements will not compromise these goals.

\section{Encouraging enterprise expenditure on training}

The second broad category of approaches to changing enterprises' views on training is focused on changing employers' attitude towards expenditure on training. The first strategy is making it more attractive to enterprises. This could range from making more relevant vocational education provisions through to providing enterprise-based learning arrangements that will augment what is provided by the publicly-funded provisions. The second is changing enterprises' views of the value of vocational learning. This includes both long and short-term measures to enhance the standing and complexity of the occasional tasks and their need for initial and ongoing development

\section{Making training more attractive to enterprises}

Enterprises may be more willing to sponsor training that they feel closely addresses their needs. Small businesses are a case in point. While small businesses are often accused of not contributing to national expenditure on training (Burke 1995), they consistently, persistently and overwhelmingly report that the existing provision of training courses fails to address their needs (Coopers \& Lybrand 1996). Consequently, there is little incentive for them to sponsor something they believe to be inappropriate and ill focused. There are also certain industry sectors that have little or no history of participation in the vocational education system. Enterprises in these sectors may well question why they should expend funds on courses not designed for the sector. Sometimes emerging industry needs are dealt with in ways that are quite distinct from existing provisions. For instance, the provision for the food processing industry in Australia is largely through workplace based training resources (Billett \& Hayes 1999). 
This is in contrast to the resources used in the institutionally based vocational education provisions afforded to the metals, hospitality and automotive industries. Therefore, to make training provision more pertinent and responsive to enterprise needs may be a way of encouraging greater enterprise engagement in vocational skill development.

There are other rationales for a more relevant system of vocational education. Firstly, the work conducted in workplaces will always be some variation of vocational practice. No enterprise exercises the archetypal vocational practice. The uniform provision of vocational education that assumes that vocational practice is enacted in a unitary way is questionable. In essence, this approach has already been part of the apprenticeship and traineeship system with the majority of the time spent in workplaces, each with their own unique curriculum. Of course, there can be serious disadvantages to this kind of arrangement. As in the United Kingdom, occupational preparation might be come so ad hoc that the development of industry-wide skills or occupation-wide skills could become eroded, with the risk to national industry development. Moreover, a system that is highly responsive to enterprises may disadvantage individuals who participate in vocational education. Students seeking vocational education to learn broad occupational skills, not just those that pertain to a particular enterprises' requirements unless they are in some way very highly remunerated or of high status. So in seeking to permit more enterprise specific skill development, the issues of conflict between overall national goals for skill development need to be weighed against the prospect of greater enterprise sponsorship of the national vocational education effort, and realising the needs and aspirations of individuals.

\section{Sharing the costs of training}

One option could be to accept that there is a need to develop both industry -wide skills and enterprise specific capacity and that the training system should reflect these twin goals. One approach would be for government to be concerned with national or industry wide skills needs and that enterprises sponsor and secure enterprise specific skill development. Such arrangements exist in France where the government takes responsibility for general vocational education provision and retraining schemes and enterprises take responsibility for training needs arising from technical and organisational change (Dubar 2000). Changes to the French training levy certainly reflect a need to distinguish between expenditure on national, regional and enterprise goals (Brochier \& Meiaux 1997 cited in Giraud, 2002). However, in practice it may be difficult to isolate those learning outcomes and learning processes that are wholly industry-wide or wholly enterprise specific. Nevertheless, it may be possible to negotiate some break-up of the cost of skills development based upon the scope of their applicability. This would involve changes to how curriculum documents are developed, the kinds of expectations arising from courses and the complex interaction at the local level between providers of vocational education and local enterprises.

This leads to the notion of 'leverage' or government spending to encourage greater financial and other contributions from employers. Examples in Australia include the "voucher" system developed in New South Wales in which small businesses are encouraged to use a $\$ 500$ training voucher from the State government to buy training from the public VET system (Collins 2003) or the TAFE Queensland Mining Services venture in Queensland in which the TAFE system share the costs of training in the mining industry with major employers (Robinson 2003). Currently, there are trends within Australia and overseas to explore how localised social partnerships can develop a responsive and robust vocational education system. The most notable example is that is that of the Local Learning and Employment Networks in Victoria, as introduced by the 
Brack's government. So there are precedents and interest in localised arrangements that could include efforts to organise enterprise specific vocational education training provisions. The difficulties here would be in identifying, balancing and organising appropriate arrangements that are acceptable to all parties.

\section{Changing enterprise perceptions about expenditure on training}

As noted, there are differences across countries in the level of enterprises' commitment and approaches to expenditure on training. Some of these differences are the product of particular cultural values or societal practices. In North America, there tends to be a higher expectation that individuals rather than enterprises will take responsibility for their vocational skill development, in ways that are remote from government policy (ILO 2000) not in references. Bishop (1997) suggests most enterprise training in the US occurs in large unionised enterprises that are experiencing growth and increasing their use of technology or their output. The recipients of this training tend to be those who are well-educated, young, recently hired, male and white. The vocational education system is less well developed than in many European countries. For instance, participation in apprenticeship programs is far more limited in the US than in other comparable economies such as those in Europe (Brunello \& Medio 2001). Yet, in Germany (Giraud 2000) and Switzerland (Schweri 2002) further training is also seen as the individual's responsibility, whereas in France individuals look to the enterprise as a sponsor of that training, and also more so in the public sector than the private. Also, given the more contingent nature of the workforce in the US, the UK and Australia, employers may be less likely to expend funds on workers who are part-time and/or contractual (Vandenheuval and Wooden, 1999). In other countries, there is an expectation about the social commitment of enterprises to training workers. For instance, in Germany and Switzerland there is likely to be a strong social press for businesses to be involved in the training and ongoing development of their workers' skills. In countries such as the Netherlands where there are strong labour laws, enterprises want to maximise the skills of their workers (which they are paying for) and, therefore, need little encouragement to invest time and effort in skilling their workers. In Scandinavia, there is a long-standing social consensus on the value of training to business and on the rights of workers to receive training from their employees throughout their working life. Employers in Denmark, Norway and Finland are not bound by central European style laws on training, but provide training as part of the employment contract with the employee, which is premised on a sentiment of social obligation. Regulation in these circumstances is more focused on the distribution of training opportunities, than the provision of training per se.

In Australia, a quite different set of perceptions exists amongst employers. It seems that the Training Guarantee Scheme led to a heightened sensitivity about the cost of training. In short, it modified employers' views about training that came to be seen as a cost. This was quite the opposite from what was intended. In Australia enterprises, to increase the level of expenditure may necessitate building up the understanding about the importance of skills and their contribution to the ongoing development for enterprises' economic viability, their communities and the country as a whole. In the shorter term, in attempting to achieve a more positive approach to enterprise contribution to their employees' skill development, government might:

- promote the need for equity in financial support for the national effort that is otherwise unfairly distributed across industry sectors;

- promote the importance of skill renewal to avoid problems of skill shortages for Australian enterprises; 
- illuminate instances of the contribution of skills to enterprise success, thereby highlighting the shared national goal of highly skilled workforce; and

- in contrast to previous approaches there is probably need to build a consensus about and commitment to expenditure on training within Australia enterprises.

In the longer term, the goal might be to change the perceptions of employers about expenditure on training. Measures here might include:

- government championing the importance of vocational knowledge and skills and the significance of skills acquisition for skilled work and national well-being;

- establishing the equivalents of trade associations and guilds that could become the advocates for vocational knowledge and the worth of its development; and

- seeking the advice and requirements of enterprises in the formulation of the curriculum development planning process, including credentialling systems.

However, beyond the goals of enhancing enterprises' commitment and contribution to the initial and ongoing development of its workers is an equally important goal. That is, for the expenditure on training by enterprises to be distributed more evenly across the workforce. Study after study (e.g. O'Connell 1999, Brunello 2001) from many countries (e.g. Groot, Hartog \& Oosterbeck 1994) note that the distribution of training opportunities in workplaces is inequitable. Often it is those who are most vulnerable and precariously placed in the workplace that miss out on training. Those most likely to secure enterprise support are often the young, the well-educated, the mobile worker who is male and white. Yet, influencing practices in decision-making in workplaces seems to be beyond the scope of most of the processes described above. Both the mandated and regulated approaches adopted in France and Germany (Giraud 2002), as well as those in Australia, have been unable to address this issue. Even when legislated requirements for enterprises to publish their annual training plans (as in Germany) or form bipartite enterprise committees to discuss training related matters often have little or no impact on enterprise decision about how training opportunities will be distributed. It is only in Singapore, where there exists a targeted program that supports socially disadvantaged workers. It remains unclear whether such a scheme could attract interest in Australia and elsewhere.

Such an equity goal will be more likely to be achieved through a process of emphasising the need for ongoing development for all workers throughout their working lives. The need for learning for a working life is not restricted to the young, welleducated and mobile. All workers increasingly require assistance in learning for their working life. The workplace is often the only and sometimes the most appropriate place to learn what is required for transforming nature of vocational practice (Billett 2002). Thus a key strategic policy goal is to enhance the standing of vocational practice, vocational knowledge and its ongoing development throughout employees' working lives. The development of this regard for vocational knowledge might encourage a more mature approach to enterprise commitment to training. Ideally, this will avoid the need for compulsion and lead to a more balanced sharing of the cost of employee development that will bring obligations and commitments to enterprises. One possible mechanism to secure this commitment is through the establishment of professional bodies that can advocate for, identify needs and play a role in policy formation. include:

In seeking to achieve this goal the policy mechanisms for government might

- acknowledging the richness and complexity of vocational practice;

- promoting in the community the attributes of significance of vocational practice; 
- assisting the formation and continuity of professional bodies that seek to promote particular forms of vocational practice;

- $\quad$ engaging and accepting the advice of such professional bodies in policy formation; and

- generating a climate in which the professional standing of vocational practice is held to be significant.

\section{Conclusion}

We have argued in this paper that there is no simple policy prescription that can be adopted either within Australia and elsewhere that will alone be sufficient to address the issue of increasing employer contributions to training. There are a range of mechanisms including levies, leverage and partnership arrangements that have all enjoyed some success. A potentially important lesson from these considerations is that commitment from employers to any policy measures is critical to their ultimate success. This implies a significant element of voluntarism, aided by government intervention to encourage and cajole, is essential to the success of policy in this area. Central to this element of voluntarism are the perceptions that employers hold about the value of vocational training.

Ultimately, decisions about expenditure of funds on training are the product of individuals' interests, values and commitments, albeit those of individuals as managers, supervisors, business owners or individuals' sponsoring their own development. It is these kinds of values that are responsive and committed to the development and sponsorship of skills. There is a danger that compulsion may serve to achieve counterproductive outcomes, such as superficial compliance or resentment towards the ongoing skill development of employees. However, when there is agreement that such measures are required, they find broad support.

In sum, an important policy goal is to enhance the standing, significance and value that individuals and enterprises place on the initial preparation and ongoing development of vocational knowledge and practice. The degree to which such knowledge and practice is valued is central to how enterprises make judgments about the costs, effort and commitment to the ongoing process of securing that knowledge throughout employees' working lives. Enhancing the standing and status of this knowledge appears as a key goal for Australia. For instance, in other countries apprentices are willing to work for longer hours and lower levels of pay to secure prized vocational knowledge. In the Netherlands and Germany, the training funds for apprenticeships are largely provided by the enterprises. Similarly, enterprises and unions are willing to collaborate to provide quality vocational education provisions to avoid interventions by government in other countries. Consequently, a key role for government might be to enhance the standing in status of vocational practice in order for enterprises to view it as a worthy investment.

\section{References}

Australian Bureau of Statistics (2003). Employer Training Expenditure and Practices, Australia. Canberra, AGPS.

Bartels A P (2000) Measuring the Employer's return on Investments in Training: Evidence from the literature. Industrial Relations vol 39 no 3.

Bertrand, O. (1993). Financial and fiscal devices to encourage the development of vocational training: A case study of France. Unpublished.

Billett, S (1994) Cost benefits of training : A Queensland study, Queensland Training Officers' Society. 
Billett, S (2002) Towards a workplace pedagogy: Guidance, participation and engagement, Adult Education Quarterly. Vol.53 no. 1 pp. 27-43.

Billett, S \& Hayes S (2000) Meeting the demand: The needs of vocational education and training clients. Adelaide NCVER. ISBN 0873975898

Bishop, J H (1997). What we know about employer provided training: A review of the literature. Research in Labour Economics 16 19-87.

Brunello, G \& Medio, A (2001) An explanation of International Differences in Education and Workplace Training. European Economic Review 45 (2) 307-322

Brunello, G (2001) On the complementarity between Education and Training in Europe. IZA discussion paper 309. (Forschungsinstituit zur Zukunft der Arbeit- IZA. (Institute for the Study of Labour)

Burke, G (1995) Some aspects of the economic evaluation of vocational education and training, in Ferrier and Selby-Smith (eds.), The economics of education and training, Canberra, AGPS.

Carnevale, A P \& Schulz, E R (1990), 'Return on investment: accounting for training', Supplement to Training \& Development Journal, July 1990.

Collins, D (2003) Personal communication, May 2003

Coopers \& Lybrand (1994) Training practices and preferences of small business in Australia: A report for vocational education and training providers, report commissioned by the Australian National Training Authority.

Coopers \& Lybrand (1996), The Economic dimensions of education and training in the member states of the European Union. - http://www.transcend.co.uk/eyll/ideas.htm.

Davidson, J, Doucouliagos, C, Macneil, J, Rimmer, M, Sgro, P \& Watts, L, (1997), Return on Training Investment. Office of Technical and Further Education/Australian National Training Authority.

Giraud, O. (2002). Firms' further training practices and social exclusion: can industrial relations systems provide greater equality? Theoretical and empirical evidence from Germany and France in K. Schoman and P.J. Connell (eds) Education, training and employment dynamics: transitional labour markets in the European Union. Cheltenham, Edward Elgar.

Groot, W, Hartog, J \& Ososterbeek H (1994) Costs and revenues of investment in EnterpriseRelated Schooling. Oxford Economic Papers, 46 (4).

Hall, R., Buchanan, J \& Considine, G (2002). 'You value what you pay for': enhancing employers' contributions to skill formation and use: a discussion paper for the Dusseldorp Skills Forum Sydney: Dusseldorp Skills Forum.

Hedge, P \& Moss, D (1996) 'Costing the effectiveness of training" case study 1-improving Parcelforce driver performance', Industrial and Commercial Training, vol 28, no.3, 1996, pp14-18.

Keep, E (2003) University of Warwick, Personal Communication, May $29^{\text {th }} 2003$

Krueger A \& Rouse C (1998) The effect of workplace education on earning, turnover and job performance. Journal of Labor Economics vol 16 (1) pp. 61-94

O’Connell P J (1999) Adults in training: An international Comparison of Continuing Education and Training, OECD Working Paper.

Robinson, C (2003). Personal communication, May 2003

Robinson, D G \& Robinson, J (1989) 'Training for impact', Training and Development Journal, vol 43, no.8, 1989, pp. 34-42.

Roffey, B, Stanger, A, Forsaith, D, McInness, E, Petrone F, Symes, C \& Xydias M (1996) Women in Small Business: A Review of Research, Small Business Research Program, Report for the Flinders University of South Australia to Dept Industry, Science and Tourism, Canberra, AGPS.

Schweri J (2002) University of Berne, Personal Communications. 12 September, Lisbon Portugal

Smith, A (1998). Training and development in Australia. $2^{\text {nd }}$ Edition. Butterworths, Sydney. Smith, A (2001). Return on investment in training: Research readings. Adelaide, NCVER. 
Smith, A \& Hayton, G. (1999). What drives enterprise training? Evidence from Australia. International Journal of Human Resource Management, 10:2. 251-72

Smith, A, \& Billett, S (2003) Enhancing employer investment in training. Adelaide, National Centre for Vocational Education Research

Smith, A., Oczkowski, E., Macklin, R and Noble, C. (2003). Organisational change and the management of training in Australian enterprises. International Journal of Training and Development, 7:1., 2-15.

Vandenheuval, A \& Wooden, M (1999). Casualisation and outsourcing: Trends and implication for work-related training. Adelaide, NCVER.

Wolf, A, (1996) The dilemma of qualifications in the workplace: what should employers pay for? Making a difference seminar series. Assessment Centre, March 1996, Sydney. 